\title{
Heterotopic Pregnancy in Natural Uninduced Cycles: A Case Series with Two Positive Outcomes in a Semi-urban Area in Cameroon
}

\author{
R Tchounzou ${ }^{1,2}$, AG Simo Wambo ${ }^{1,2}$, T Nana Njamen ${ }^{1,3}$, François Dadao ${ }^{5}$, Felix Elong ${ }^{1,4}$, T Egbe \\ Obintchemti $^{1,3}$, Gregory Halle Ekane ${ }^{1,3}$ \\ Department of Obstetrics and Gynaecology, ${ }^{1}$ Faculty of Health Sciences, University of Buea; ${ }^{2}$ Regional Hospital Limbe, \\ Maternity service; ${ }^{3}$ Douala General Hospital; ${ }^{4}$ Regional Hospital Bue; ${ }^{5}$ Regional Hospital Garoua, Cameroon.
}

\section{Corresponding Author: \\ Dr. R Tchounzou \\ Email: rtchounzou@yahoo.fr}

This is an Open Access article distributed under the terms of the Creative Commons Attribution License (creativecommons.org/ licenses/by/3.0).

Received : May 9, 2018

Accepted : November 3, 2018

Published : November 20, 2018

\begin{abstract}
Background: Heterotopic pregnancy is a rare occurrence in natural uninduced pregnancy, representing about 1/30,000 live deliveries. In remote areas where diagnostic and therapeutic resources like ultrasonography and laparoscopy are scarce, the intra-uterine component often results in miscarriage. Case Report: We report on a series of three consecutive cases out of 5987 live births with two positive outcomes. Conclusion: We conclude that in our settings the incidence of heterotopic pregnancy is high due to high prevalence of pelvic inflammatory diseases and recommend that during laparotomy for ectopic pregnancy, minimal trauma should be caused to uterus to safeguard a potential intra-uterine pregnancy.
\end{abstract}

Keywords: Abortion, Heterotopic Pregnancy, Live Birth, Pelvic Inflammatory Disease, Uterus.

\section{Introduction}

The incidence of heterotopic pregnancy is in the rise with the advent of assisted medical procreation. In natural uninduced cycle, it is still a rare event accounting for about $1 / 30000$ pregnancies $[1,2]$. Most of the time, diagnosis of intra-uterine pregnancy is made retrospectively during the emergent laparotomy for ruptured ectopic pregnancy [3]. Many cases of heterotopic pregnancies reported in the literature are due to the use of clomiphene citrate for induction of ovulation or in the context of assisted reproductive technology (ART) [1,4]. If the condition is diagnosed pre-operatively with the use of ultrasound or laparoscopy and surgical techniques with minimal trauma to the uterus applied, the outcome of intra-uterine pregnancy development is good $[5,6]$. In poor countries with limited access to modern diagnostic and therapeutic tools like ultrasound and laparoscopic equipment, cases of heterotopic pregnancies reported usually result into wastage of intra-uterine pregnancy.
We report on three cases with two consecutive term deliveries after total salpingectomies for ampullary ruptured ectopic pregnancies in a period of six years from August 2009 to August 2015 in the Limbe regional hospital.

\section{Case Reports}

\section{Case 1}

A 26 year old patient, G1P0, with imprecise last menstrual period consulted for amenorrhea and metrorrhagia and was diagnosed of missed abortion at ultrasound. She benefited from uterine evacuation by means of aspiration and the product of conception sent for pathology confirmed picture of missed abortion. On discharge, patient complained of pelvic pains one week after, of increasing intensity associated to vomiting, fatigue. These symptoms prompted hospitalization in a peripheral hospital where she received a treatment including pains killers with no remarkable effect 
on pains. The patient was referred back to us when the pains became unbearable.

Physical examination elucidated an anxious patient well oriented in time, space and person; vital signs were stable (BP 118/70 $\mathrm{mm} \mathrm{Hg}$, pulse $84 / \mathrm{min}$, temperature $37.2^{\circ} \mathrm{C}$ ). A pelvic painful mass deviated to left; about $10 \mathrm{~cm}$ of diameter was felt on vaginal examination. We clinically suspected torsion of ovarian cyst or uterine fibroid. An urgent ultrasound demonstrated a left tubal pregnancy with a living fetus of 12 weeks. An emergency laparotomy was done which confirmed the ruptured left ampullary pregnancy with hemoperitoneum of $200 \mathrm{ml}$. Left total salpingectomy was performed and the post-operative period was uneventful [Fig.1,2].

\section{Case 2}

A woman of 30 years old, with two living children and one abortion was received in the emergency unit with clinical picture of hemoperitoneum confirmed by a paracentesis and a positive pregnancy test. In the course of the surgery during which we performed a right total salpingectomy, we suspected an intrauterine pregnancy. We avoided grasping the uterus with Hysterolap and thus did little manipulation on the uterus. The contralateral adnexae were macroscopically normal and there were no pelvic adhesions. In the immediate post-operative period a pelvic ultrasound was performed which confirmed a nine weeks and three days gestation. Etiological investigations included a Chlamydia serology which depicted a positive IgG at 1/128, vaginal smear and sensitivity test and urogenital Mycoplasma which were negative. The patient was placed on natural progesterone $200 \mathrm{mg}$ /day for 11 weeks. She benefited from a monthly antenatal visit and the pregnancy evolved uneventfully to normal vaginal delivery at 39 weeks of a live female baby.

\section{Case 3}

A 32 years old mother of one child with past medical history of secondary infertility of five

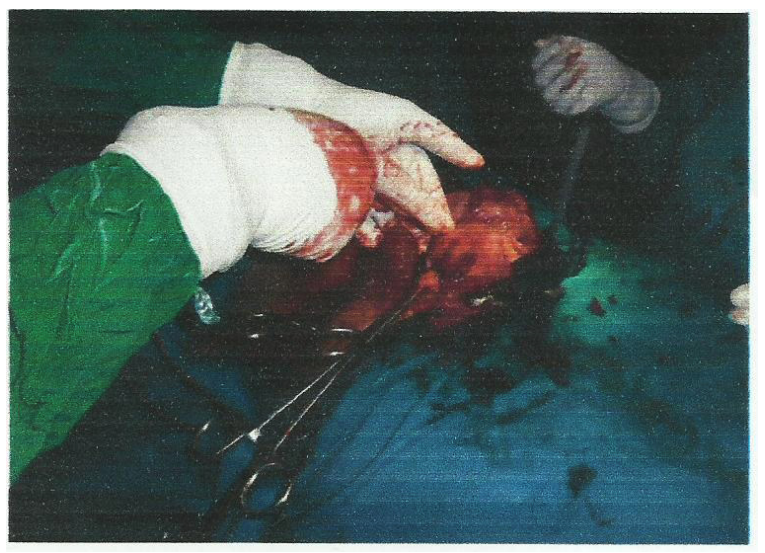

Fig.1: Left ampullary ruptured ectopic pregnancy, ruptured during operation, fetus still in the amniotic pouch.

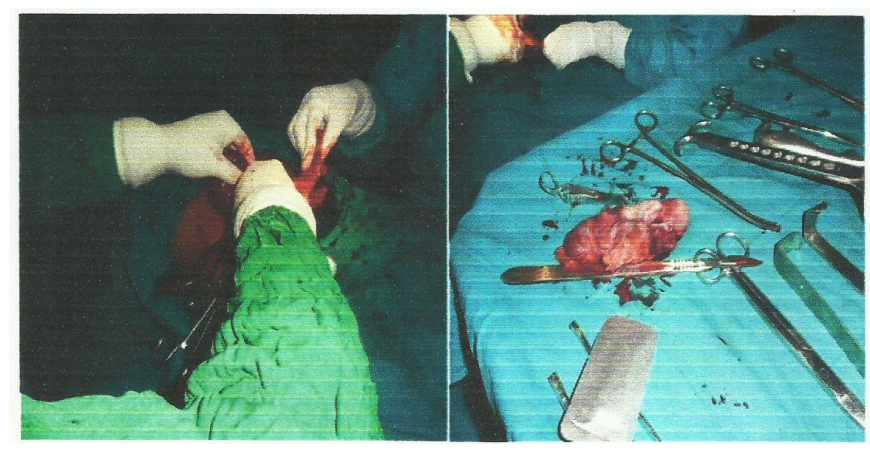

Fig.2: Salpingectomy with live fetus.

years duration was rushed into the emergency unit of the hospital with severe abdominal pains, fainting on eight weeks and two days amenorrhea. The vital parameters on arrival were unstable with a blood pressure of $78 / 55 \mathrm{~mm} \mathrm{Hg}$ and a pulse rate of 116 beats per minute; examination of abdomen demonstrated signs of distension and tenderness in favour of a peritoneal collection. A paracentesis was performed which revealed 10 millilitres of uncoagulable blood. The patient was operated the same day after cross-matching blood for eventual transfusion. Intra-operative findings included a right ampullary ruptured pregnancy, hemoperitoneum of $600 \mathrm{ml}$, flimsy pelvic adhesions involving fallopian tubes and small bowel, the contralateral tube was macroscopically normal; the uterus was increased in size. 
We did right total salpingectomy after gentle adhesiolysis and aspiration of hemoperitoneum; little manipulation was done on the uterus. In the post-operative period, an ultrasound was done and an intra-uterine pregnancy of eight weeks described. A full blood count done showed a picture of normocytic anaemia of $7.4 \mathrm{~g} / \mathrm{dL}$ but the patient refused blood transfusion thus was put on hematinics. Since she was keeping records of recent positive Chlamydia serology, no other investigations was done. The antenatal care consisted of a monthly check and the pregnancy progressed to term. She underwent an elective caesarean section at 39 weeks because of her unfavourable obstetric history and the outcome was a healthy male baby.

\section{Discussion}

Heterotopic pregnancy incidence is in the increase in the world with the development of assisted reproductive technologies (ART) but in the natural conception, this entity is still a very rare event $[1,2,7]$. The reported incidence of heterotopic pregnancy in natural conception is about $1 / 30000$ live deliveries [1,2]. In our series we registered an incidence of three cases out of 5987 deliveries (1/1996) over a period of six years. This high incidence can be attributed to increasing incidence of pelvic inflammatory infections in our settings and the use of citrate of clomiphene (and sometimes the agonists of FSH) for ovulation induction in disorderly manner by patients. All the three patients of our series have positive Chlamydia serology and these factors have been described by many other authors like risk factors of ectopic and heterotopic pregnancies [1,8-10].

Most cases of ectopic pregnancies are diagnosed in our setting at the ruptured stage with hemo-peritoneum which warrants urgent laparotomy [11]. Kenfack et al. reported 92\% of cases of ectopic pregnancies diagnosed when it is already ruptured $[9,10]$. In these conditions, heterotopic when it exists is often diagnosed retrospectively or in the course of surgery for the ruptured ectopic pregnancy. In 2 out of 3 cases, the diagnosis of heterotopic pregnancy was suspected during the emergency and life-saving laparotomy for treatment of ruptured ectopic pregnancy and the related shock. In such conditions, the outcome of the intra-uterine pregnancy depends on the trauma caused to the uterus or not. When the treatment of extra-uterine pregnancy is done through laparoscopy, minimal trauma is caused to the uterus and the outcome of intrauterine pregnancy can be up to $70 \%$ of viable term babies [5]. In the two cases which resulted into term deliveries, we suspected the presence of intra-uterine pregnancy based on the increased size of uterus and we minimized the manipulation of the uterus. Intra-uterine pregnancies were confirmed by echography in the early post-operative period. Due to the urgency of the situation and lack of financial means, no ultrasound was done before surgical intervention, the diagnosis being confirmed by paracentesis. In the first case, the extra-uterine component was missed despite the ultrasonography. This is consistent with the report of some authors that ultrasound can miss the diagnosis in absence of high index of suspicion [12]. Progesterone therapy (200 $\mathrm{mg} /$ day) was prescribed to the patients during the post-operative period although the supporting effect of progesterone on early pregnancy is controversial in the literature [13].

\section{Conclusion}

Heterotopic pregnancy incidence in natural conception is high in our milieu as compared to developed countries probably due to higher incidence of pelvic inflammatory diseases (PID). In remote areas, the diagnosis of intra-uterine pregnancy is usually done during the laparotomy for ruptured ectopic pregnancy. If minimal trauma is caused to the uterus during the surgery, the concomitant intra-uterine pregnancy can result in term viable baby. 
Contributors: RT, AGSW received and managed the cases, designed and wrote the report; TNN, FD, FE did manuscript revision and literature search; TEO, GHE: critical inputs into the manuscript. RT will act as guarantor of the study. All the other authors read and approved the final version of this manuscript.

Funding: None; Competing interests: None stated.

\section{References}

1. Tripathi JB, Patel BS, Rawal SA, Garg SJ. Undiagnosed case of term heterotopic pregnancy with ectopic abdominal pregnancy. Indian Med Assoc. 2011;109:764765.

2. Govindarajan MJ, Rajan R. Heterotopic pregnancy in natural conception. J Hum Reprod Sci. 2008;1(1):37-38.

3. Silva PD, Meisch AL. Laparoscopic treatment of heterotopic pregnancy. J Am Assoc Gynecol Laparosc. 1995;2(2):213-216.

4. Simsek T, Dogan A, Simsek M, Pestereli E. Heterotopic triplet pregnancy (twin tubal) in a natural cycle with tubal rupture: case report and review of the literature. $\mathrm{J}$ Obstet Gynaecol Res. 2008;34(4 Pt 2):759-762.

5. Kably Ambe A, Werner von der Meden Alarcón J, García León JF, Reyes Cuervo H. Early diagnosis of heterotopic pregnancy with viability of the intrauterine fetus. Report of two cases and review of the literature. Ginecol Obstet Mex. 1995;63:346-348.

6. Soriano D, Vicus D, Schonman R, Mashiach R, ShasharLevkovitz D, Schiff E, et al. Long-term outcome after laparoscopic treatment of heterotopic pregnancy: 19 cases. J Minim Invasive Gynecol. 2010;17:321-324.
7. Shih HM, Li YT, Yeh KC, Hsu KP. Combined pregnancy: a case report and literature review. Zhonghua Yi XueZaZhi (Taipei). 1993;52:58-61.

8. Kigbu JH, Sagay AS, Chingle PM. Heterotopic pregnancy at term masquerading as intrauterine twin gestation, a case report. Niger J Clin Pract. 2009;12:324326.

9. Korkontzelos I, Antoniou N, Stefos T, Kyparos I, Lykoudis S. Ruptured heterotopic pregnancy with successful obstetrical outcome: a case report and review of the literature. Clin Exp Obstet Gynecol. 2005;32:203206.

10. Siklós P, Lázár E, Petik D, Sebestyén A, Pálfalvi L, Ungár L. Successful outcome of an intrauterine twin pregnancy combined with ectopic pregnancy. Orv Hetil. 2000;141:2251-2253.

11. Kenfack B, Noubom M, Bongoe A, Tsatedem FA, Ngono M, Nguefack Tsague G, et al. Ectopic pregnancy in a semi-rural area in Africa: Epidemiological, clinical and therapeutic aspects about a series of 74 cases treated at the district hospital of Sangmelima in southern Cameroon. Pan Afr Med J. 2012;13:71.

12. Giacomello F, Larciprete G, Valensise H, Romanini C. Spontaneous heterotopic pregnancy with live embryos: an insidious echographic problem in the first trimester. Therapeutic problems. A clinical case and review of the literature. Minerva Ginecol. 1998;50:151-155.

13. Daya S. Efficacy of progesterone support for pregnancy in women with recurrent miscarriage. A meta-analysis of controlled trials. BJOG. 1989;96(3):275-280. 